\title{
New national medical electives portal
}

$\mathrm{M}$ edical students will soon be able to browse and apply for visiting electives at schools across Canada using a single web portal. The portal, which was initiated by the Association of Faculties of Medicine of Canada (AFMC), will feature a centralized application service and guide to available elective opportunities across Canada. Students will be able to upload their documentation, search for placements, apply electronically and track school responses.

The aim is to provide a "one-stop shop" for elective applications, says Dr. Geneviève Moineau, AFMC president and CEO. "When functional, the portal will save students hours and hours of work."

Currently, students must contact medical faculties individually to inquire about and apply for elective placements. There is no national database of available placements, and each school has its own subtly different application processes and requirements.

For students applying for more than one placement, "it can be very tedious and difficult to coordinate, particularly as schools now require much more documentation, such as police checks and immunization records," says Moineau. International students face particular difficulties, as "obviously their dossiers may be more complex to process."

According to Jesse Kancir, president of the Canadian Federation of Medical Students, these difficulties shape students' elective choices. "There are situations where students decide not to apply out east or west, for example, because it just becomes too burdensome."

Reducing this administrative burden may encourage students to cast a wider net when applying for electives, he says.

All 17 of Canada's medical faculties have signed on to use the new portal. AFMC will begin roll-out to a small number of schools in late summer 2014. The portal will be open to Canadian and international medical students at the beginning of their studies for a one-time fee of $\$ 150$.

"Having that career planning tool starting in first-year medicine will be brilliant," says Kancir. "If you're able to find out a year or two in advance who is offering placements for, say, pediatric plastic surgery, it helps you plan and make connections before applying."

Kancir hopes that the common application portal will lead faculties to standardize requirements for placements. "Discussions around standardization have definitely happened, but maybe it will take students and faculties directly comparing policies across the country to see more movement."

The ability to track the status of applications through the new portal will also hold schools more accountable for response times, he adds.

According to Moineau, medical faculties are still hashing out shared "rules of functioning" under the new system, but "issues of timeliness" are being discussed. — Lauren Vogel, CMAJ

\section{CMAJ 2014. DOI:10.1503/cmaj.109-4835}

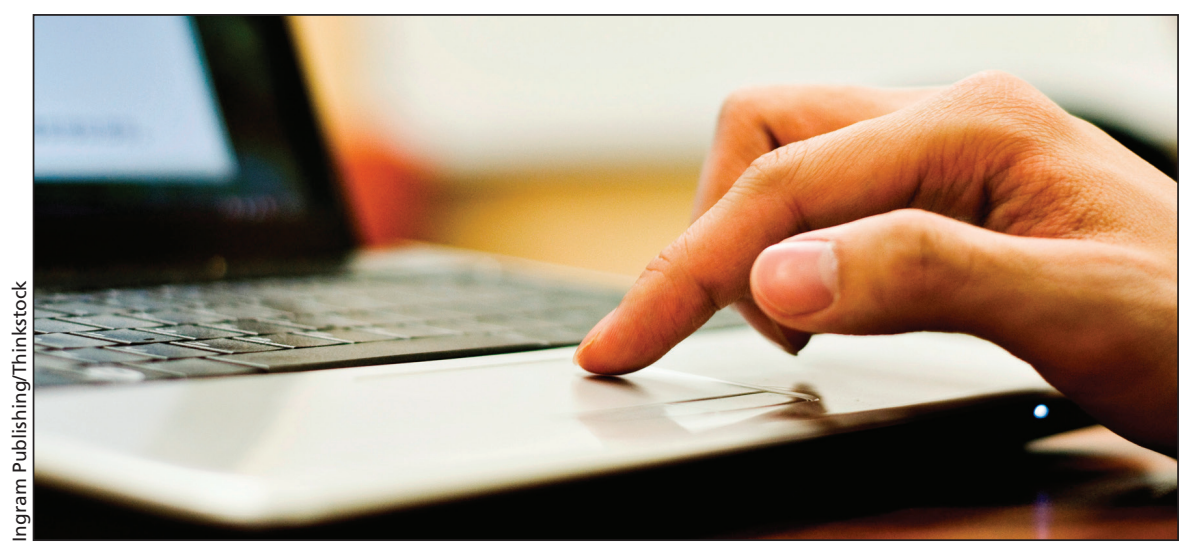

A new web portal will save medical students hours researching and applying for visiting electives at schools across Canada. 